\title{
Expression profiling of transcription factors Pax-5, Oct-1, Oct-2, BOB.1, and PU.1 in Hodgkin's and non-Hodgkin's lymphomas: a comparative study using high throughput tissue microarrays
}

\author{
Ryan C McCune, Sergei I Syrbu and Mohammad A Vasef \\ Department of Pathology, University of Iowa Hospital and Clinics, Iowa City, IA, USA
}

\begin{abstract}
Analysis of B-cell-specific transcription factors is useful in understanding of the differentiation-linked phenotype in Hodgkin's as well as in non-Hodgkin's lymphomas. We analyzed the expression profiling of transcription factors Pax-5, Oct-1, Oct-2, BOB.1, and PU.1 in 109 cases, including non-Hodgkin's lymphomas of $B$ - and T-lineage, classical Hodgkin's lymphomas, and nodular lymphocyte predominant Hodgkin's lymphomas. Our study revealed that all transcription factors were universally expressed in all cases of nodular lymphocyte predominant Hodgkin's and variably expressed in non-Hodgkin's lymphomas of B-lineage. Cases of classical Hodgkin's lymphoma variably expressed the Pax-5, Oct-1, Oct-2, and BOB.1. However, in contrast to nodular lymphocyte predominant Hodgkin's lymphoma, the transcription factor PU.1 was consistently absent in all cases of classical Hodgkin's lymphoma. Transcription factors Pax-5, BOB.1, and PU.1 were not detectable in cases of anaplastic large cell lymphoma. However, the Oct-1 was detected in all anaplastic large cells lymphoma cases, indicating that expression of this transcription factor was not restricted to B-lineage lymphoid malignancies. Our findings suggest that inclusion of the PU.1 antibody may prove useful in separating classical Hodgkin's lymphomas from nodular lymphocyte predominant Hodgkin's lymphomas in problematic cases. Modern Pathology (2006) 19, 1010-1018. doi:10.1038/modpathol.3800622; published online 28 April 2006
\end{abstract}

Keywords: B-cell transcription factors; Hodgkin's lymphoma; non-Hodgkin's lymphoma; tissue microarray

The neoplastic cells in non-Hodgkin's lymphoma and nodular lymphocyte predominant Hodgkin's lymphoma express B-cell-specific antigens, immunoglobulin mRNA transcripts, and their proteins. ${ }^{1}$ In contrast, Reed-Sternberg and Hodgkin's cells in classical Hodgkin's lymphoma, despite their rearranged immunoglobulin genes, fail to express functional immunoglobulin mRNA and/or protein, and lack B-cell-specific antigens in most instances. ${ }^{1-4}$ It has been speculated that the lack of immunoglobulin mRNA transcripts and immunoglobulin protein expression, as well as B-cell specific antigens may be due to either crippling mutations of the immunoglobulin genes found in approximately $25 \%$ of

Correspondence: Dr MA Vasef, MD, Department of Pathology, 1 University of New Mexico, MSC08 4640, Albuquerque, NM 87131, USA.

E-mail: MVasef@salud.unm.edu

Received 22 December 2005; revised 9 April 2006; accepted 10 April 2006; published online 28 April 2006 cases, ${ }^{2,5-7}$ or downregulation and disruption of the B-cell-specific transcription factors. ${ }^{8-10}$

Recent studies have shown that transcription factors Pax-5, Oct-1, Oct-2, BOB.1, and PU.1 are expressed in the majority of B-cell lymphomas and nodular lymphocyte predominant Hodgkin's lymphoma, but are downregulated in Reed-Sternberg and Hodgkin's cells of classical Hodgkin's lymphoma. ${ }^{1-3,8-10}$ Most studies report that the Pax5 is expressed in $100 \%$ of non-Hodgkin's lymphomas of B-lineage and a significant proportion of classical Hodgkin's lymphoma. However, there is inconsistency in the reported incidence of expression of the Oct-2, Oct-1, BOB.1, and PU.1 in classical Hodgkin's and non-Hodgkin's lymphomas in the literature.

To further characterize the expression profile of transcription factors Pax-5, Oct-1, Oct-2, BOB.1, and PU.1, we performed immunohistochemistry on tissue microarray constructs consisting of 40 cases of classical Hodgkin's lymphoma, 11 nodular lymphocyte predominant Hodgkin's lymphoma, 10 
follicular lymphoma, 14 diffuse large B-cell lymphoma, 11 mantle cell sell lymphoma, 9 small lymphocytic lymphoma, 3 marginal zone B-cell lymphoma, 9 anaplastic large cell lymphoma, and 2 precursor T-cell acute lymphoblastic lymphoma.

The neoplastic cells in all nodular lymphocyte predominant Hodgkin's lymphoma cases expressed the PU.1 whereas the Reed-Sternberg and Hodgkin's cells in all classical Hodgkin's lymphoma cases failed to express the PU.1. This finding confirms and further expands prior observations. ${ }^{1,10-13}$ In addition, the neoplastic cells in all nodular lymphocyte predominant Hodgkin's lymphoma cases consistently expressed the BOB.1. In contrast, only a minority of Reed-Sternberg and Hodgkin's cells in classical Hodgkin's lymphoma weakly expressed the BOB.1. All transcription factors were expressed in the majority of non-Hodgkin's lymphomas of B-lineage in this study. However, about $50 \%$ of the diffuse large B-cell lymphoma cases failed to express the transcription factor PU.1. The PU.1negative cases included four CD30-positive anaplastic variant of diffuse large B-cell lymphoma.

\section{Materials and methods}

\section{Pathological Specimens}

From the files of the department of pathology at the University of Iowa Hospitals and Clinics, 109 cases were selected and representative paraffin embedded tissue blocks were retrieved for construction of tissue microarrays. The cases included 40 classical Hodgkin's lymphoma (22 mixed cellularity and 18 nodular sclerosis), 11 nodular lymphocyte predominant Hodgkin's lymphoma, 47 mature B-cell non-Hodgkin's lymphomas of different types, 9 anaplastic large cell lymphoma, and 2 precursor T-cell acute lymphoblastic lymphoma.

\section{Tissue Microarray Constructs}

Hematoxylin and eosin stained slides from all 109 cases were reviewed to localize precisely the target areas of the tumor in corresponding paraffin embedded tissue blocks for inclusion within the tissue microarray. The tissue microarray was made using a manually operated machine that uses two separate needles for punching the donor and recipient blocks (Beecher Instruments, Silver Spring, MD, USA). Tissue cylinders $(0.6 \mathrm{~mm}$ in diameter) retrieved from the donor blocks were oriented within the recipient block using the instrument's X-Y micrometer adjustment knobs. Four cores from each donor block were punched and oriented into the recipient blocks. The completed recipient block was incubated at $37^{\circ} \mathrm{C}$ for $20 \mathrm{~min}$ to facilitate adhesion of the tissue cores to the paraffin.

\section{Immunohistochemical Study}

Sections of the tissue microarray blocks were mounted onto positively charged slide, baked at $56^{\circ} \mathrm{C}$ for $60 \mathrm{~min}$, deparaffinized in xylene, rehydrated in graded alcohols, and rinsed. For heatinduced epitope retrieval, the tissue sections were placed in $10 \mathrm{mM}$ citrate buffer at $\mathrm{pH} 6.0$ (Pax-5, Oct1 , Oct-2, and BOB.1), or in ethylenediaminetetraacetic acid antigen retrieval solution at $\mathrm{pH} 8.0$ (PU.1), and heated in a microwave oven for two cycles of $5 \mathrm{~min}$ each, or three cycles of $5 \mathrm{~min}$ each, respectively. After cooling the sections for $20 \mathrm{~min}$ at room temperature, endogenous peroxidase activity was blocked using hydrogen peroxide/methanol, and for the prevention of nonspecific background staining, blocking serum was applied (Santa Cruz staining kit). The sections were then incubated with the monoclonal antibodies to the Oct-1 (clone 12F11, Santa Cruz Biotechnology, Santa Cruz, CA, USA), the PU.1 (clone G148-74, Pharmingen, San Diego, CA, USA), the Pax-5 (clone 24, Transduction Laboratories, Lexington, KY, USA), and polyclonal antibodies to the Oct-2 and BOB.1 (Santa Cruz Biotechnology, Santa Cruz, CA, USA) at the following dilutions: 1:10 (Oct-1) and 1:50 (PU.1, Oct-2, Pax-5, BOB.1) for 30-60 min at room temperature. For the detection of bound primary antibodies either the streptavidin-biotin (LSAB-DAKO) or the EnVision technique (DakoCytomation; Carpinteria, CA, USA) with diaminobenzidine chromogen as a substrate was used. Sections of a tonsil with reactive lymphoid hyperplasia served as positive and negative controls.

\section{Results}

The results of expression profile of transcription factors Pax-5, Oct-1, Oct-2, BOB.1, and PU.1 in Hodgkin's and non-Hodgkin's lymphomas are summarized in Table 1.

\section{Histopathologic Findings}

Sections of the tissue microarray blocks were stained with hematoxylin and eosin and compared with routine sections from the original donor blocks to assure that adequate representative tumor cells were present for evaluation. Only cases that had at least two out of four tissue cores with adequate tumor were included in the study. Expression of the Pax-5, Oct-1, Oct-2, BOB.1, and PU.1 was scored by counting the number of positive cells and the signal intensity. Positivity was defined as nuclear staining of at least $1 / 3$ of the neoplastic cells and the intensity of staining was graded as low, moderate, and high. The occasional cytoplasmic staining seen with some antibodies was considered as nonspecific and considered as negative. 
Table 1 Expression of transcription factors Pax-5, Oct-2, Oct-1, BOB.1, and PU.1 in Hodgkin and non-Hodgkin's lymphomas

\begin{tabular}{|c|c|c|c|c|c|}
\hline & $P a x-5$ & Oct-2 & Oct-1 & BOB.1 & PU.1 \\
\hline NLP Hodgkin & $11 / 11(100 \%)$ & $11 / 11(100 \%)$ & $11 / 11(100 \%)$ & $11 / 11(100 \%)$ & $11 / 11(100 \%)$ \\
\hline Classic Hodgkin & $26 / 40(65 \%)$ & $29 / 39(74 \%)$ & $25 / 37(67 \%)$ & $7 / 37(19 \%)$ & $0 / 40(0 \%)$ \\
\hline FL & $10 / 10(100 \%)$ & $10 / 10(100 \%)$ & $10 / 10(100 \%)$ & $10 / 10(100 \%)$ & $10 / 10(100 \%)$ \\
\hline DLBCL & $14 / 14(100 \%)$ & $14 / 14(100 \%)$ & $14 / 14(100 \%)$ & $14 / 14(100 \%)$ & $7 / 14(50 \%)$ \\
\hline MCL & $10 / 11(91 \%)$ & $9 / 11(82 \%)$ & $11 / 11(100 \%)$ & $9 / 11(82 \%)$ & $11 / 11(100 \%)$ \\
\hline SLL & $9 / 9(100 \%)$ & $8 / 9(83 \%)$ & $9 / 9(100 \%)$ & 9/9 (100\%) & $9 / 9(100 \%)$ \\
\hline MZBCL & $3 / 3(100 \%)$ & $3 / 3(100 \%)$ & $3 / 3(100 \%)$ & $3 / 3(100 \%)$ & $3 / 3(100 \%)$ \\
\hline T-ALL & $0 / 2(0 \%)$ & $0 / 2(0 \%)$ & $2 / 2(100 \%)$ & $0 / 2(0 \%)$ & $2 / 2(100 \%)$ \\
\hline ALCL & $0 / 9(0 \%)$ & $1 / 9(11 \%)$ & $7 / 9(78 \%)$ & $0 / 9(0 \%)$ & $0 / 9(0 \%)$ \\
\hline
\end{tabular}

NLP, nodular lymphocyte predominant; FL, follicular lymphoma; DLBCL, diffuse large B-cell lymphoma; MCL, mantle cell lymphoma; SLL, small lymphocytic lymphoma; MZBCL, marginal zone B-cell lymphoma; T-ALL, Precursor T-cell acute lymphoblastic lymphoma; ALCL, anaplastic large cell lymphoma.

\section{Immunohistochemical Findings}

Pax-5 expression

In tonsil with reactive lymphoid hyperplasia, the Pax-5 was strongly expressed in lymphocytes residing in mantle zone. The Pax-5 was also expressed with weak to moderate intensity in germinal center cells (Figure 1). Virtually, all cases of Hodgkin's lymphoma of B-lineage demonstrated a moderate to strong nuclear staining for the Pax-5 (Figures 2 and 3 ), with the exception of one case of mantle cell lymphoma, which was completely negative. The neoplastic cells of nodular lymphocyte predominant Hodgkin's lymphoma showed positive nuclear staining with moderate intensity in more than $90 \%$ of the malignant cells in all cases examined (Figure 1). The Reed-Sternberg and Hodgkin's cells in most mixed cellularity Hodgkin's lymphoma cases $(77 \%)$ showed a weak to moderate nuclear staining, while only $50 \%$ of nodular sclerosis Hodgkin's lymphoma expressed the Pax-5 (Figure 1). All cases of anaplastic large cell lymphoma and precursor T-cell acute lymphoblastic lymphoma were Pax-5-negative (Figure 3).

\section{OCT-1 and OCT-2 expression}

A moderate to strong nuclear positivity was found in germinal center cells in tonsil with reactive lymphoid hyperplasia for the Oct-1 and Oct-2 transcription factors. The B-cells in mantle zone and interfollicular regions showed a less intense nuclear staining. In all cases of Oct-1- and Oct-2-positive non-Hodgkin's lymphoma and classical Hodgkin's lymphoma, the intensity of the Oct-2 staining was always higher than that seen with the Oct-1 (Figures 1-3). Similar to the Pax-5, the Oct-1 and Oct-2 were more frequently expressed in mixed cellularity than nodular sclerosis type of Hodgkin's lymphoma. The Oct-2 appeared to be more B-lineage restricted and only one case of T-lineage anaplastic large cell lymphoma demonstrated weak nuclear immunoreactivity for this transcription factor. In contrast, the Oct- 1 was expressed in seven of nine T-lineage anaplastic large cell lymphoma and 2 T-lineage acute lymphoblastic lymphoma cases, indicating that this transcription factor is not restricted to B-cells (Figure 3). Both Oct-1 and Oct-2 were expressed in neoplastic cells of all 11 cases of nodular lymphocyte predominant Hodgkin's lymphoma with stronger reactivity observed with the Oct-2 (Figure 1).

\section{BOB.1 expression}

The BOB.1 was expressed in germinal center cells in tonsil with reactive lymphoid hyperplasia with moderate intensity and was variably expressed in mantle zone and interfollicular cells with a lowintensity pattern. Except for two mantle cell lymphoma cases that did not express the BOB.1, the remaining nine cases, and all B-lineage non-Hodgkin's lymphomas of the nongerminal center phenotype including small lymphocytic lymphoma, and marginal zone B-cell lymphoma expressed the BOB.1 with weak to moderate intensity (Figures 2 and 3). The lymphomas of germinal center origin including follicular lymphoma, Burkitt lymphoma, and germinal center-derived diffuse large b-cell lymphoma universally demonstrated a strong nuclear staining pattern. The BOB.1 was expressed weakly in only a small subset of mixed cellularity (26\%) and nodular sclerosis Hodgkin's lymphomas $(11 \%)$. In contrast to classical Hodgkin's lymphoma, all cases of nodular lymphocyte predominant Hodgkin's lymphoma expressed the BOB.1 with a moderate to strong intensity (Figure 1). All nine anaplastic large cell lymphoma cases were negative for the BOB.1

\section{PU.1 expression}

The PU.1 was expressed by germinal center cells in tonsil with reactive lymphoid hyperplasia with moderate intensity and with weaker intensity in mantle zone lymphocytes. The scattered histiocytes in interfollicular areas demonstrated the PU.1 expression with the strongest intensity as expected. All small B-cell neoplasms and nodular lymphocyte predominant Hodgkin's lymphoma cases expressed the PU.1 (Figures 1-3) with a particularly stronger 

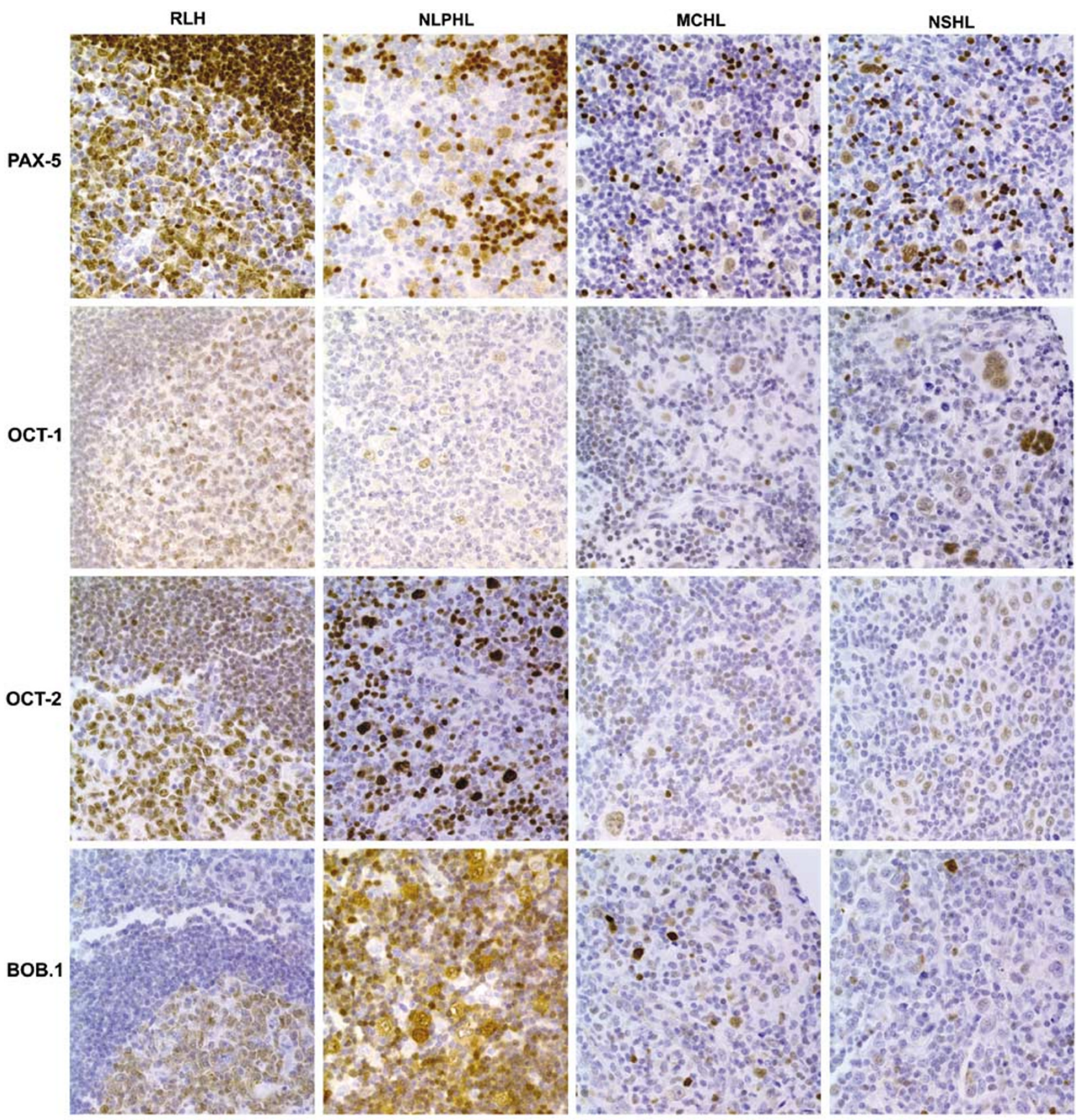

BOB.1
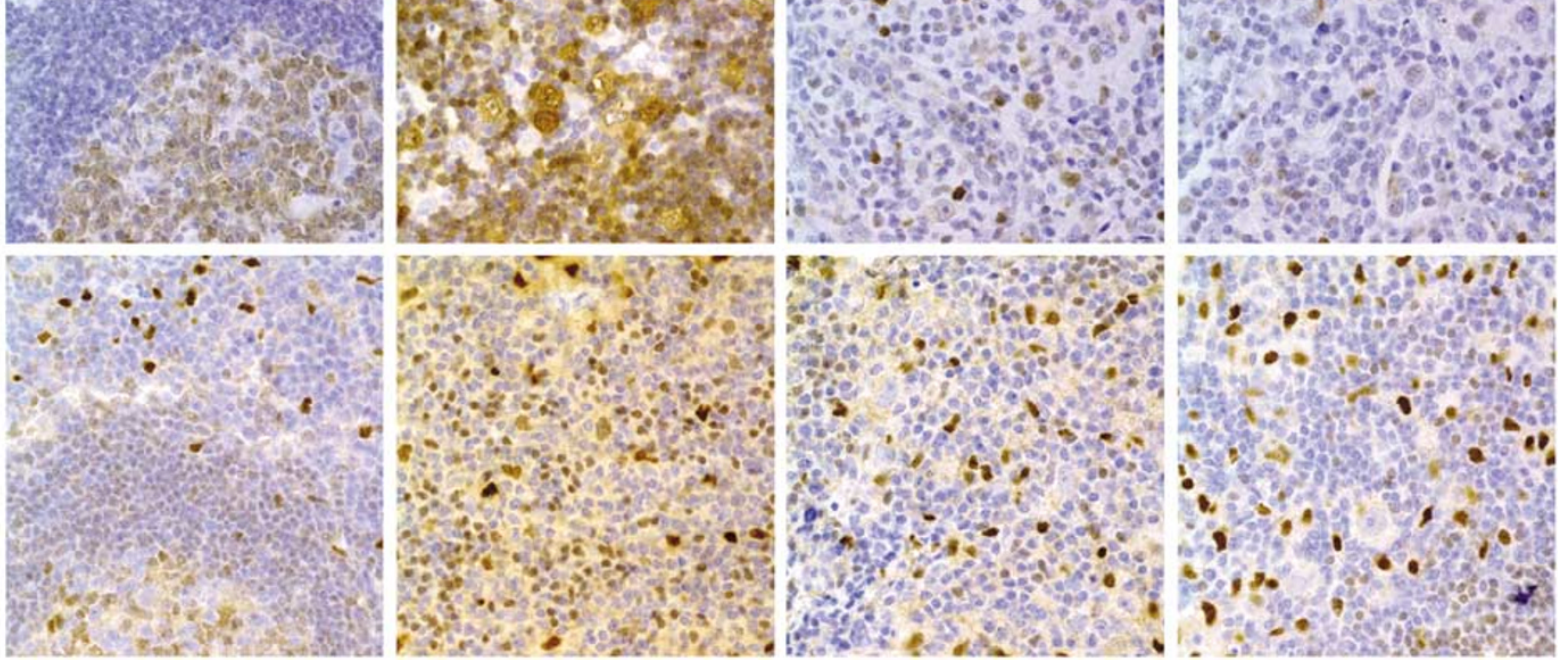

Figure 1 Immunohistochemical staining pattern of the transcription factors Pax-5, Oct-1, Oct-2, BOB.1, and PU.1 in reactive lymphoid hyperplasia (RLH), nodular lymphocyte predominant Hodgkin's lymphoma (NLPHL), mixed cellularity Hodgkin's lymphoma (MCHL), and nodular sclerosis Hodgkin's lymphoma (NSHL). The neoplastic cells in NLPHL are PU.1-positive. In contrast, the neoplastic cells in classical Hodgkin's are PU.1-negative. Original magnification, $\times 400$. 

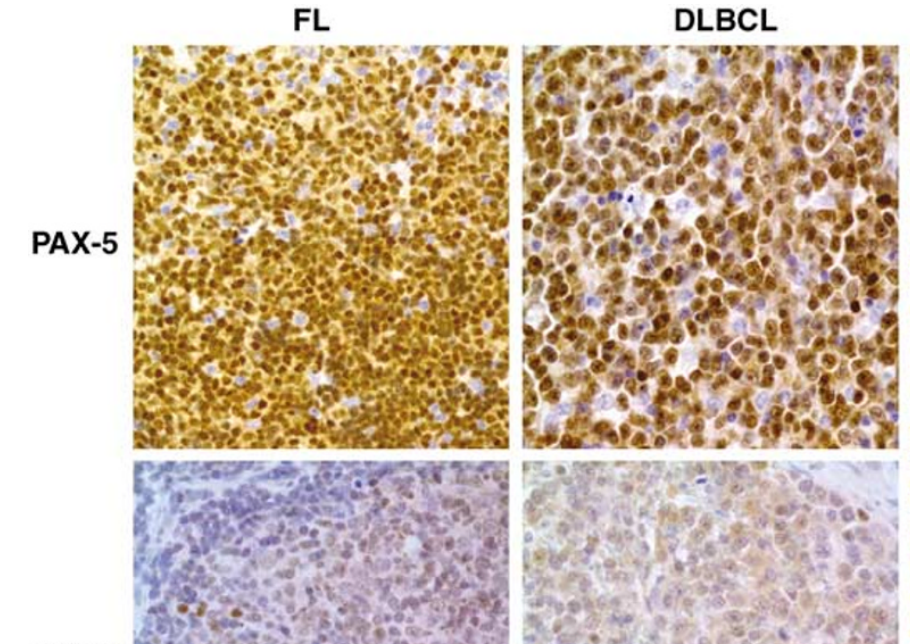

OCT-1

ОСТ-2
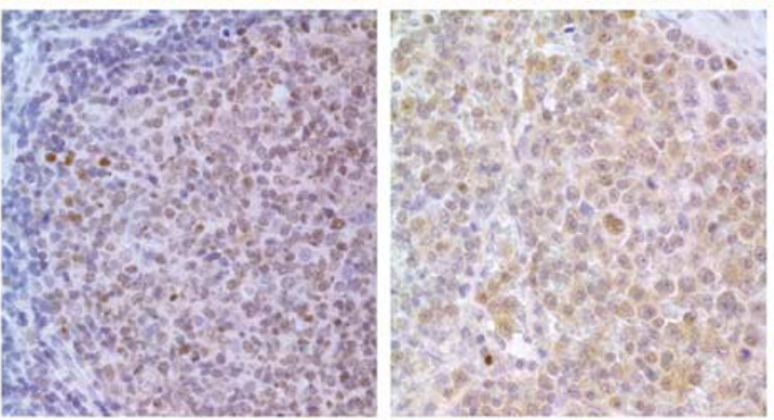

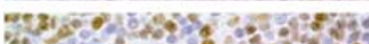
Hoing and Hos

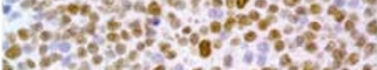
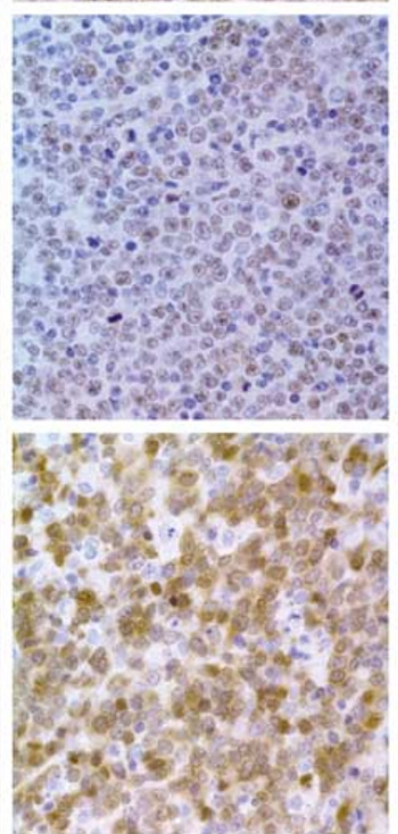

вов.
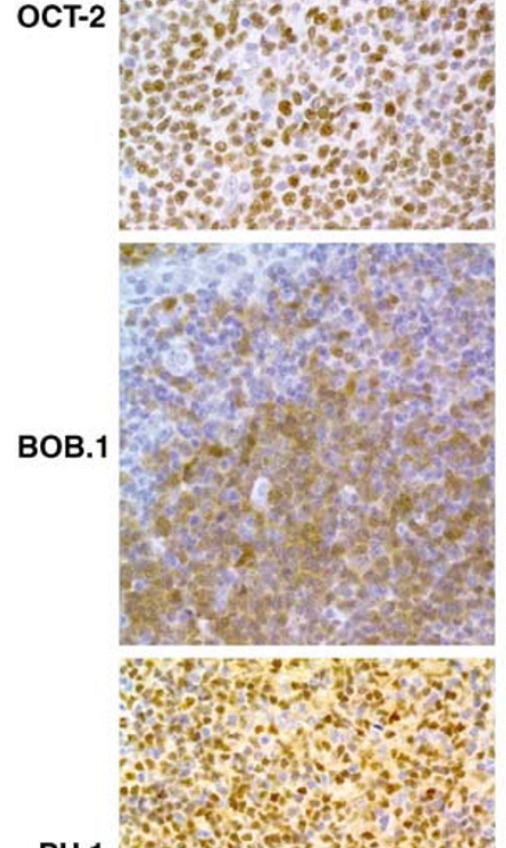

PU.1

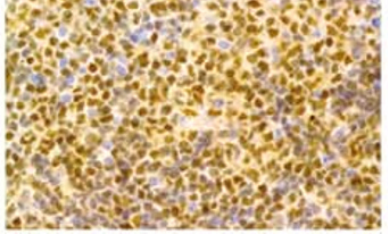

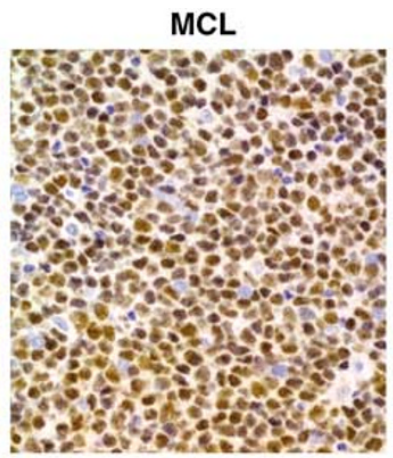

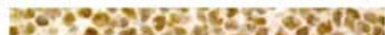
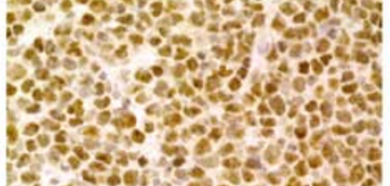

C. E.

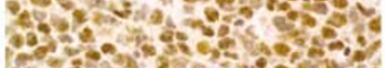
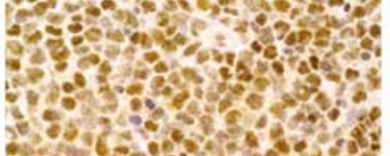

s.t.
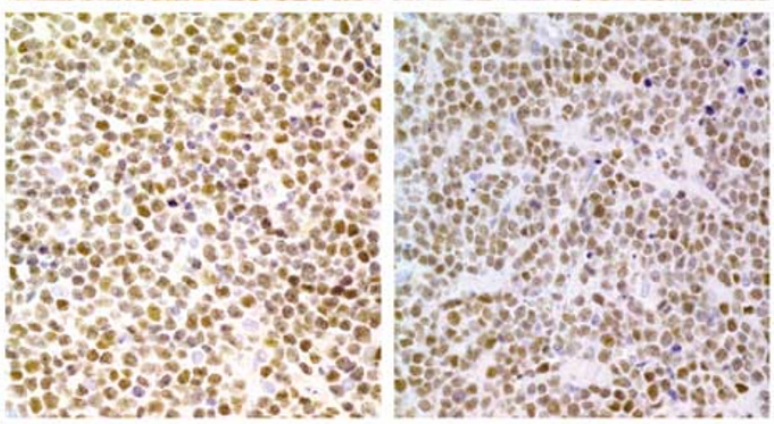

6.8.
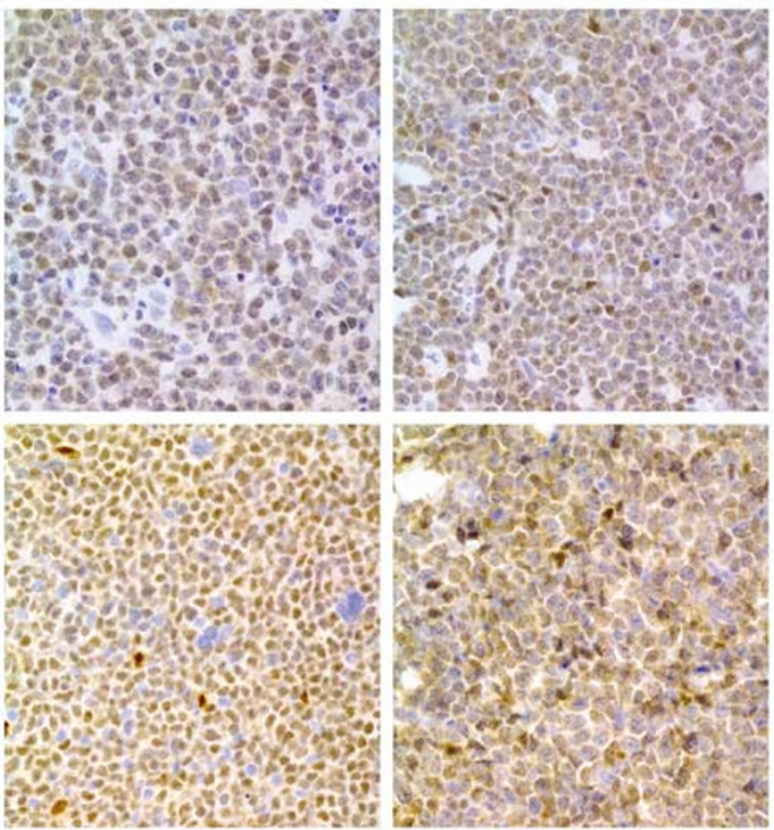

Figure 2 Immunohistochemical staining pattern of the transcription factors Pax-5, Oct-1, Oct-2, BOB.1, and PU.1 in follicular lymphoma (FL), diffuse large B-cell lymphoma (DLBCL), mantle cell lymphoma (MCL), and Burkitt lymphoma. All the transcription factors including PU.1 are expressed in the majority of these subtypes of B-lineage non-Hodgkin’s lymphomas. Original magnification, $\times 400$. 


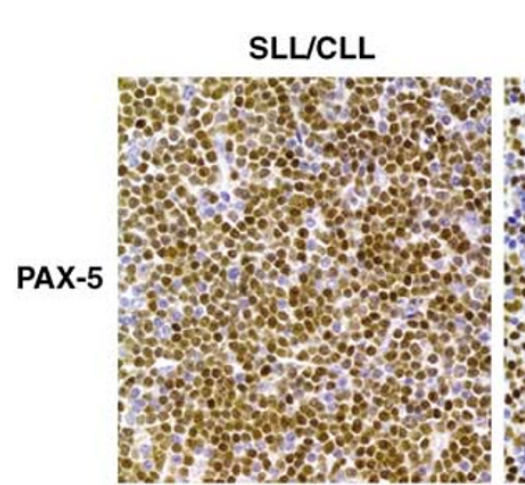

MZBCL

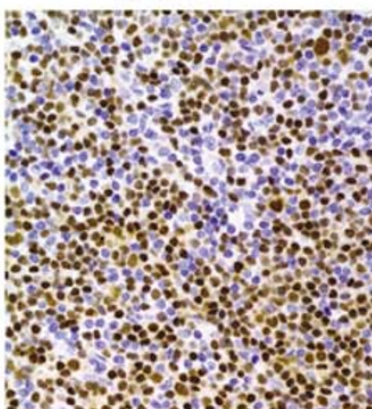

OCT-1
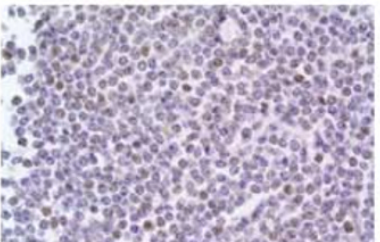

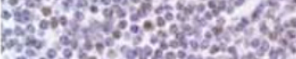

Hostom

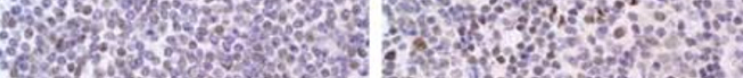

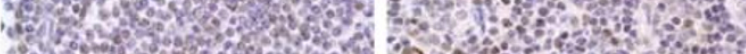
H.

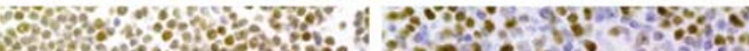

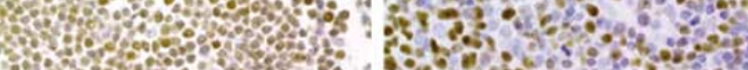
H. H H

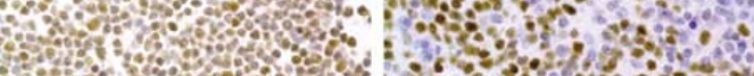

OCT-2
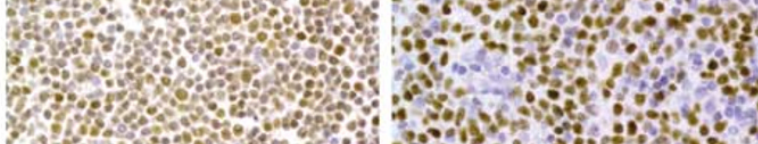

\%6
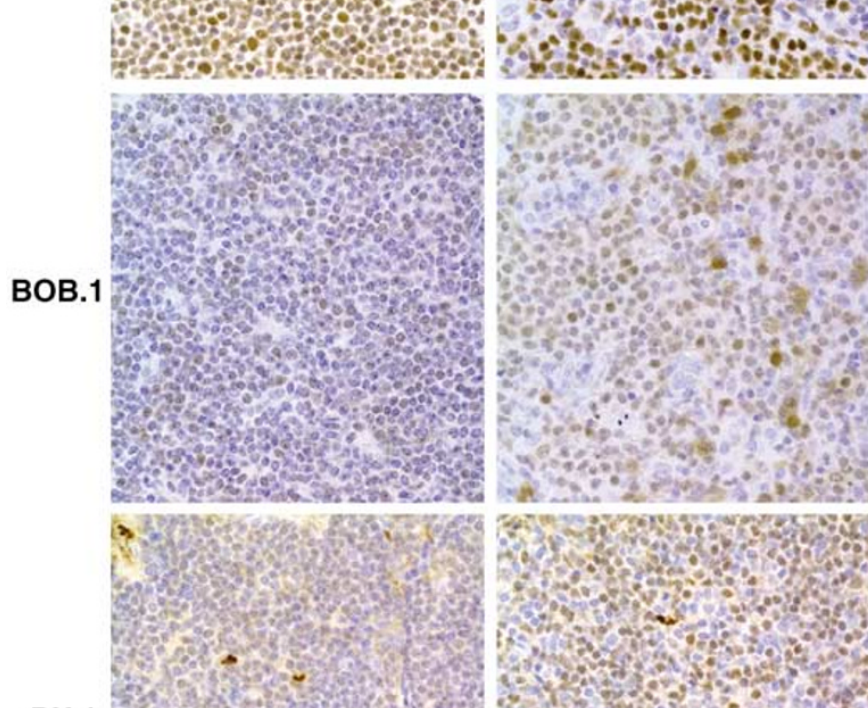

PU.1
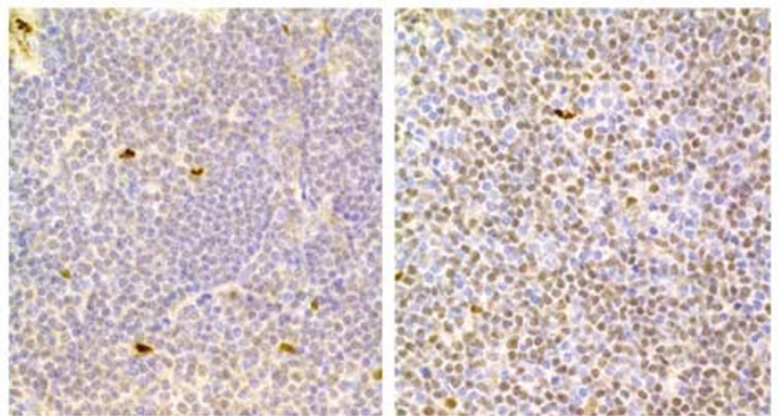

T-ALL
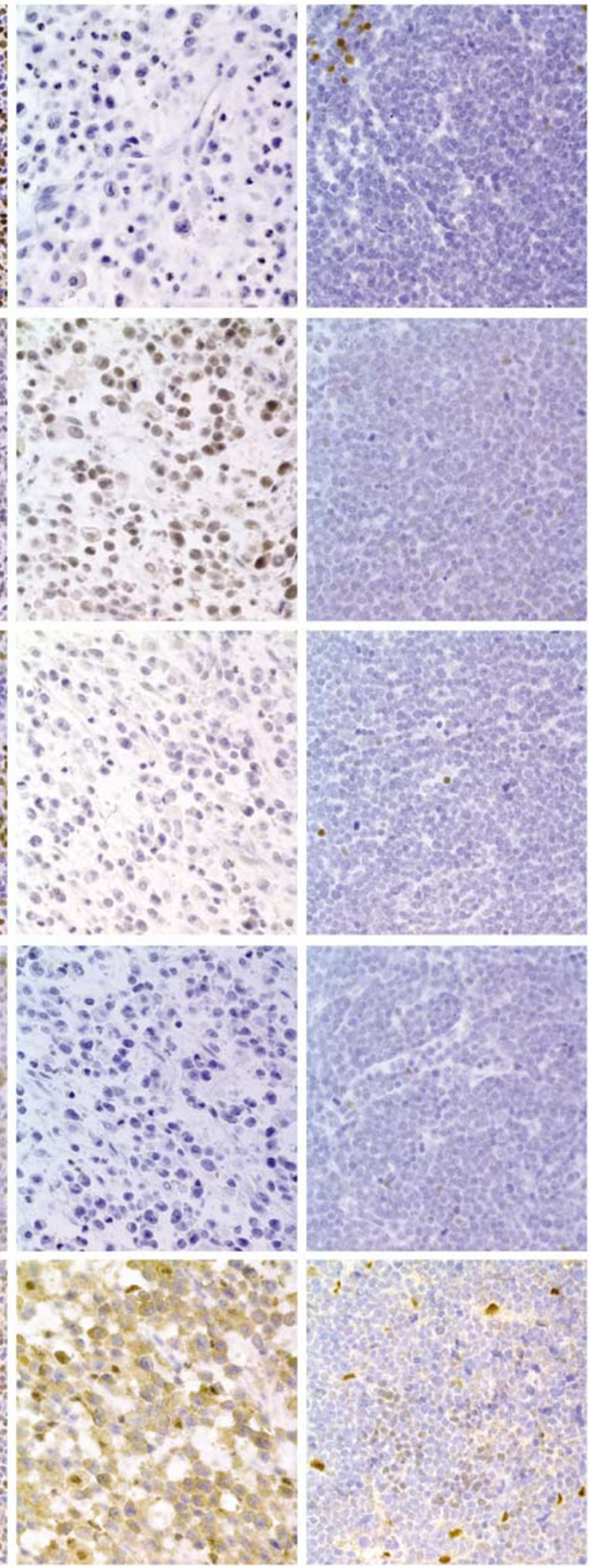

Figure 3 
intensity in centroblastic cells of the follicular lymphoma cases. In diffuse large B-cell lymphoma cases, the PU.1 was expressed with weak to moderate intensity in only seven of 14 cases. The PU.1-positive cases were more frequent in the centroblastic variant of diffuse large B-cell lymphoma. In contrast, all four cases of CD30positive anaplastic variant of diffuse large B-cell lymphoma were PU.1-negative. The classical Hodgkin's lymphoma and T-lineage anaplastic large cell lymphoma cases were all negative for the PU.1, while two cases of precursor T-cell acute lymphoblastic lymphoma displayed weak to moderate immunoreactivity (Figures 1 and 3).

\section{Discussion}

The differentiation and proliferation of B-cells are controlled by a network of lineage-restricted transcriptional factors. The first step in commitment of pluripotent progenitor cells to the lymphoid lineage cells results in the formation of the common lymphoid progenitors. The transcription factor PU.1 plays an essential role in the development of both lymphoid and myeloid lineages ${ }^{14}$ by regulating IL-7 receptor or macrophage-colony stimulating factor. Low levels of PU.1 expression upregulate IL-7 receptor expression on common lymphoid progenitor cells, while high levels of PU.1 prevent IL-7 receptor expression. ${ }^{15}$

IL-7 receptor expressing common lymphoid progenitor cells give rise to all lymphocyte subsets including B-, T-, and natural killer (NK) cells.

The Pax-5 protein also known as B-cell-specific activator protein (BSAP) regulates expression of the downstream transcription factors such as Oct-1, Oct-2 and BOB.1. Both, Oct-1 and Oct-2 bind to the octamer sequence ATGCAAAT located in the immunoglobulin heavy and light chain variable region promoter and the enhancer in the intron between the joining and constant regions. ${ }^{16}$ The transactivation potential of Oct- 1 and Oct-2 is enhanced by interactions with B-cell-specific coactivator BOB.1. ${ }^{17}$

Prior studies have shown that despite their rearranged immunoglobulin genes, the Reed-Sternberg and Hodgkin's cells in classical Hodgkin's lymphoma fail to express functional immunoglobulin mRNA transcripts. In addition, in a significant proportion of classical Hodgkin's lymphoma, the Reed-Sternberg and Hodgkin's cells lack B-cellspecific antigens. ${ }^{1-4}$ The lack of immunoglobulin
mRNA transcripts and proteins as well as B-cell specific antigens have been speculated to be due to either crippling mutations of the immunoglobulin genes found in about $25 \%$ of cases,,$^{2,5-7}$ or downregulation and disruption of the B-cell-specific transcription factors. ${ }^{8-10}$ In contrast to classical Hodgkin's lymphoma, the neoplastic cells in nonHodgkin's lymphomas of B-lineage and nodular lymphocyte predominant Hodgkin's lymphoma express B-cell-specific antigens, immunoglobulin mRNA transcripts and their proteins. ${ }^{1}$

Analysis of the transcription factors involved in B-cell differentiation is useful in understanding of the differentiation-linked phenotype in nonHodgkin's and Hodgkin's lymphomas. The expression profile of transcription factors Pax-5, Oct- 1 , Oct-2, BOB.1, and PU.1 is thought to correlate with the lineage and/or the stage of the lymphoid cell differentiation. To further characterize the association between expression of these transcription factors in Reed-Sternberg and Hodgkin's cells and their lack of immunoglobulin mRNA transcripts and/or B-cell-associated antigens, we analyzed the expression of all these transcription factors in classical Hodgkin's lymphoma as well as in nodular lymphocyte predominant Hodgkin's lymphoma, non-Hodgkin's lymphoma of B-lineage, T-lineage anaplastic large cell lymphoma, and precursor T-cell acute lymphoblastic lymphoma.

The results of our study reveal that the transcription factor Pax-5 is B-lineage restricted and is expressed virtually in all types of mature B-cell non-Hodgkin's lymphoma, nodular lymphocyte predominant Hodgkin's lymphoma, and in approximately $65 \%$ of the classical Hodgkin's lymphoma. The Pax-5 is absent in T-cell neoplasms, ${ }^{18}$ including the nine anaplastic large cell lymphoma and the two precursor T-cell acute lymphoblastic lymphoma cases we studied (Table 1). Our results agree with prior observations reported by most investigators, ${ }^{11,18-21}$ but contradicts to certain extent with Krenacs et $a l^{19}$ results who reported a lower rate of expression of the Pax-5 in some subtypes of B-cell lymphomas. The discrepancy may be attributed to the use of polyclonal antibodies in their study, while the other studies including the current one used a monoclonal antibody thought to be more sensitive in detecting the Pax-5 in paraffin-embedded tissue sections.

Similar to the Pax-5, the transcription factors Oct1 and Oct-2, and BOB.1 were expressed in virtually all B-lineage non-Hodgkin's lymphoma and nodular lymphocyte predominant Hodgkin's lymphoma as

Figure 3 Immunohistochemical staining pattern of the transcription factors Pax-5, Oct-1, Oct-2, BOB.1, and PU.1 in small lymphocytic lymphoma/chronic lymphocytic leukemia (SLL/CLL), nodal marginal zone B-cell lymphoma (MZBCL), anaplastic large cell lymphoma (ALCL), and precursor T-cell acute lymphoblastic leukemia (T-ALL). Similar to NLPHL and B-lineage lymphomas in Figures 1 and 2, all the transcription factors including PU.1 are expressed in both SLL/CLL and MZBCL. In contrast, the neoplastic cells in ALCL are negative for these transcription factors except for the Oct-1. Similar to ALCL, the neoplastic cells in T-ALL are positive for the Oct-1 and negative for the Pax-5, Oct-2, and BOB.1. However, in contrast to ALCL, the neoplastic cells in T-ALL are PU.1-positive. Original magnification, $\times 400$. 
well as a variable numbers of classical Hodgkin's lymphoma cases (67, 74, and 19\% respectively). In addition, the transcription factor Oct-1 was also detected in two precursor T-cell acute lymphoblastic lymphoma and seven of nine anaplastic large cell lymphoma cases indicating that the Oct-1 is not lineage specific. Expression of the Oct-1 in T-lineage lymphoid neoplasms has been reported by others as well. ${ }^{22,23}$ The expression of the Oct-1 in both B- and T-cell derived lymphomas makes this marker less useful in the differential diagnosis of these entities. The T-lineage cases in this study were all negative for BOB.1 and Oct-2 except in one anaplastic large cell lymphoma case that weakly expressed Oct-2.

The transcription factor PU.1 was universally expressed in all neoplastic cells of nodular lymphocyte predominant Hodgkin's lymphoma, follicular lymphoma, mantle cell lymphoma, small lymphocytic lymphoma, and marginal zone B-cell lymphoma cases studied. The PU.1 was also detected in seven of 14 cases of diffuse large B-cell lymphoma. The T-lineage anaplastic large cell lymphoma cases were all negative for this transcription factor. However, the PU.1 was expressed in the two precursor T-cell acute lymphoblastic lymphoma cases studied. The PU.1 was not detected in any of the classical Hodgkin's lymphoma cases $(0 / 40)$.

In summary, we analyzed expression of transcription factors Pax-5, Oct-1, Oct-2, BOB.1, and PU.1 in B-lineage non-Hodgkin's lymphoma, classical Hodgkin's lymphoma, nodular lymphocyte predominant Hodgkin's lymphoma, anaplastic large cell lymphoma, and precursor T-cell acute lymphoblastic lymphoma. These transcription factors play crucial role in B-cell development and differentiation, as well as in maintenance of B-cell identity. Based on our results and others, ${ }^{11,17,18}$ it appears that expression of the Pax-5 is limited to B-cell lymphomas including subset of CHL with a relatively high sensitivity. The Pax-5 can separate classical Hodgkin's lymphoma from Hodgkin-like anaplastic large cell lymphoma because none of the nine anaplastic large cell lymphoma cases in our study expressed the Pax-5 whereas 26 of 40 classical Hodgkin's lymphoma cases were Pax-5-positive. This observation supports the algorithmic approach proposed by Browne et al, including the utility of the Pax-5 antibody in separating anaplastic large cell lymphoma from classical Hodgkin's lymphoma. ${ }^{11}$ Also, the Pax-5 can establish the B-cell lineage of rare cases of CD20negative immunoblastic variant of diffuse large Bcell lymphoma, including those that arise in the setting of human immunodeficiency virus (authors' observation). Therefore, the inclusion of the Pax-5 antibody in the panel of routinely used antibodies may prove useful as an additional marker for assessment of the lineage. We also find that the transcription factor PU.1 is a useful marker in differentiating classical Hodgkin's lymphoma from nodular lymphocyte predominant Hodgkin's lymphoma in problematic cases because all 11 nodular lymphocyte predominant Hodgkin's lymphoma cases in this study expressed PU.1 whereas none of 40 cases of classical Hodgkin's lymphoma were positive for this marker.

\section{References}

1 Loddenkemper C, Anagnostopoulos I, Hummel M, et al. Differential $\mathrm{E} \mu$ enhancer activity and expression of BOB.1/OBF.1, Oct2, PU.1, and immunoglobulin in reactive B-cell populations, B-cell non-Hodgkin lymphomas, and Hodgkin lymphomas. J Pathol 2004;202:60-69.

2 Marafioti T, Hummel M, Foss H-D, et al. Hodgkin and Reed-Sternberg cells represent an expansion of a single clone originating from a germinal center B-cell with functional immunoglobulin gene rearrangements but defective immunoglobulin transcription. Blood 2000;15:1443-1450.

3 Tzankov A, Zimpfer A, Pehrs A-C, et al. Expression of B-cell markers in classical Hodgkin lymphoma: a tissue microarray analysis of 330 cases. Mod Pathol 2003;16:1141-1147.

4 Vasef MA, Alsabeh R, Medeiros LJ, et al. Immunophenotype of Reed-Sternberg and Hodgkin's cells in sequential biopsy specimen of Hodgkin's disease: a paraffin-section immunohistochemical study using the heat-induced epitope retrieval method. Am J Clin Pathol 1997;108:54-59.

5 Kuppers R, Klein U, Hansmann ML, et al. Cellular origin of human B-cell lymphomas. N Engl J Med 1999;341:1520-1529.

6 Jox A, Zander T, Kuppers R, et al. Somatic mutations within the untranslated regions of rearranged Ig genes in a case of classical Hodgkin's disease as a potential cause for the absence of Ig in the lymphoma cells. Blood 1999;93:3964-3972.

7 Kanzler H, Kuppers R, Hansmann ML, et al. Hodgkin and Reed-Sternberg cells in Hodgkin's disease represent the outgrowth of a tumor clone derived from (crippled) germinal center B cells. J Exp Med 1996;184:1495-1505.

8 Theil J, Laumen H, Marafioti T, et al. Defective octamer-dependent transcription is responsible for silenced immunoglobulin transcription in Reed-Sternberg cells. Blood 2001;97:3191-3196.

9 Stein H, Marafioti T, Foss H-D, et al. Down-regulation of BOB.1/OBF.1 and Oct2 in classical Hodgkin disease but not in lymphocyte predominant Hodgkin disease correlates with immunoglobulin transcription. Blood 2001;97:496-501.

10 Re D, Muschen M, Ahmadi T, et al. Oct-2 and Bob-1 deficiency in Hodgkin and Reed Sternberg cells. Cancer Res 2001;61:2080-2084.

11 Browne P, Petrosyan K, Hernandez A, et al. The B-cell transcription factors BSAP, Oct-2, and BOB.1 and the pan-B-cell markers CD20, CD22, and CD79a are useful in the differential diagnosis of classic Hodgkin lymphoma. Am J Clin Pathol 2003;120: 767-777.

12 Jundt F, Kley K, Anagnostopoulos I, et al. Loss of PU.1 expression is associated with defective immunoglobulin transcription in Hodgkin and Reed-Sternberg 
cells of classical Hodgkin disease. Blood 2002;99: 3060-3062.

13 Hertel CB, Zhou XG, Hamilton-Dutoit SJ, et al. Loss of $B$ cell identity correlates with loss of B cell-specific transcription factors in Hodgkin/Reed-Sternberg cells of classical Hodgkin lymphoma. Oncogene 2002;21: 4908-4920.

14 Scott EW, Simon MC, Anastasi J, et al. Requirement of transcription factor PU.1 in the development of multiple hematopoietic lineages. Science 1994;265: 573-1577.

15 DeKoter RP, Singh H. Regulation of B lymphocyte and macrophage development by graded expression of PU.1. Science 2000;288:1439-1441.

16 Matthias P. Lymphoid-specific transcription mediated by the conserved octamer site: who is doing what? Semin Immunol 1998;10:155-163.

17 Laumen $H$, Nielsen PJ, Wirth T. The BOB.1/OBF. 1 co-activator is essential for octamer-dependent transcription in B cells. Eur J Immunol 2000;30: $458-469$.

18 Torlakovic E, Torlakovic G, Nguyen PL, et al. The value of anti-Pax-5 immunostaining in routinely fixed and paraffin-embedded sections. A novel pan
pre-B and B-cell marker. Am J Surg Pathol 2002;26: 1343-1350.

19 Krenacs L, Himmelmann AW, Quintanilla-Martinez L, et al. Transcription factor B-Cell-Specific Activator Protein (BSAP) is differentially expressed in B cells and in subsets of B-Cell lymphomas. Blood 1998;92: 1308-1316.

20 Foss HD, Reusch R, Demel G, et al. Frequent expression of the B-cell-specific activator protein in ReedSternberg cells of classical Hodgkin's disease provides further evidence for its B-cell origin. Blood 1999;9: 3108-3113.

21 Torlakovic E, Tierens A, Dang HD, et al. The transcription factor PU.1, necessary for B-cell development, is expressed in lymphocyte predominance, but not classical Hodgkin's disease. Am J Pathol 2001;159: 1807-1814.

22 Saez AI, Artiga MJ, Sanchez-Beato M, et al. Analysis of octamer-binding transcription factors Oct2 and Oct1 and their coactivator BOB.1/OBF.1 in lymphomas. Mod Pathol 2002;15:211-220.

23 Marafioti T, Ascani S, Pulford K, et al. Expression of Blymphocyte-associated transcription factors in human T-cell neoplasms. Am J Pathol 2003;162:861-871. 